\title{
DALGIÇ POMPALARDA YAPAY SİNİR AĞLARI KULLANILARAK DENEYSEL AKIŞ ANALİZİ
}

\author{
$\underline{1 \text { Menderes KALKAT }}{ }^{(0)} \underline{2}$ Veli TOM \\ ${ }^{1}$ Niğde Ömer Halisdemir Üniversitesi, Mühendislik-Mimarlkk Fakültesi, Makine Mühendisliği Bölümü, Niğge, \\ TÜRKIYY \\ ${ }^{2}$ Tomhisar Pompa Mak. San. Tic. Ltd. Şti. \\ 1'mkalkat@ohu.edu.tr, 2vefatom@gmail.com
}

(Geliş/Received: 24.09.2019; Kabul/Accepted in Revised Form: 01.11.2019)

ÖZ: Makale kapsamında, derin kuyu su pompalarının su debisinin deneysel akış analizi, yapay sinir ağları kullanılarak gerçekleştirilmiştir. Pompanın en önemli parametresi olan debi verisi debimetre ile elde edildi. Elde edilen veriler kullanılarak yapay sinir ağı modeli ile yeni modeller oluşturuldu. Aktarılan veriler ve programın oluşturduğu grafikler gerçekte oluşturulan veriler ile birbirlerine uyumlu olduğu gözlemlenmektedir. Sonuç olarak, pompaların arızası yapay sinir ağı ile yapılan debi girişleri ile tespit edilebilir ve sonrasında pompanın, de-montajı gerçekleştirilip direk arızalı kısma müdahale edilebilecek seviyeye gelinebilir.

Anahtar kelimeler: Derin kuyu pompası, yapay sinir ağları, debi, dalgı̨̧ pompa, pompa arızası

\section{Experimental Flow Analysis Using Artificial Neural Networks In Submersible Pumps}

\begin{abstract}
Article coverage, the flow analysis of the flow of deep well water pumps was carried out using artificial neural networks. Flow data of the pumps were measured by using flowmeter. Data obtained were used as desired values for neural network predictor. The desired data and the graphics created by the neural network were found to be compatible with the data actually found. As a result, the failure of the pumps can be determined by flow inputs to the neuarl network predictor and then the pump can be installed and the defective part can be intervened.
\end{abstract}

Key words: Deep well pump, artificial neural networks, flow rate, submersible pump, pump failure

\section{GİRIŞ̧ (INTRODUCTION)}

Yeraltında sıcak ve soğuk su kaynakları vardır. Kullanım amacıyla bu suların yeryüzüne çıkarılması gerekmektedir. İhtiyaca göre derinlikte kuyular açılmak suretiyle, kuyu dibine indirilen pompalar yardımıyla yeryüzüne su çıkarılır (Gölcü, 2002). Kuyular Şekil 1' de görüldüğü üzere sondaj makinaları yardımı ile açılır. 


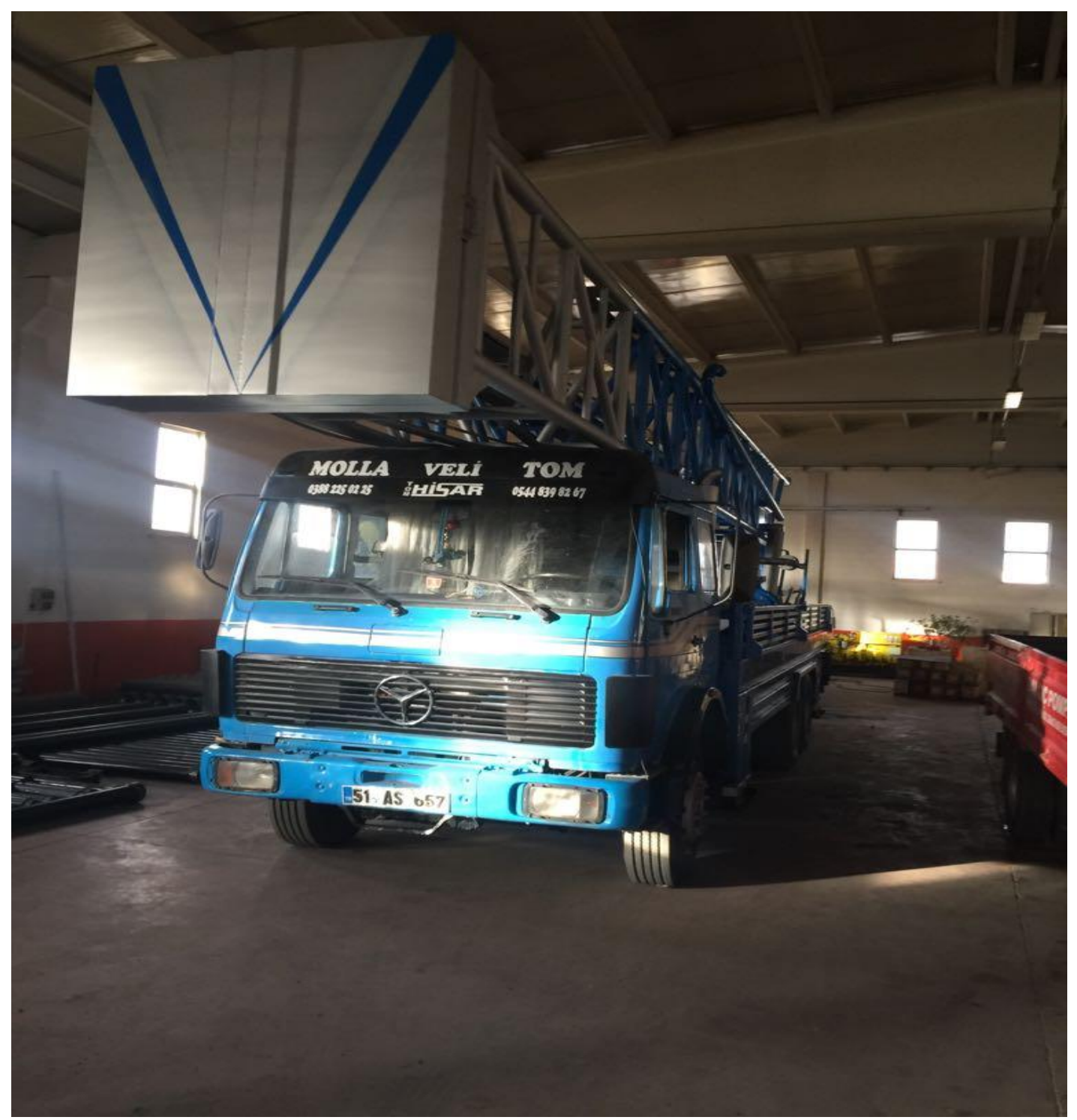

Şekil 1. Sondaj Makinası

Figure 1. Well Drilling Machine

Pompa seçiminde; su rezervi (yer altı suyu, kuyu, nehir yatağı, havuz vb ), pompalanacak su miktarı, toplam emme yüksekliği ve toplam dinamik yükseklik göz önünde bulundurulması gerekli hususlardır. Yer altı suyunun bulunduğu derinliğe bağlı olarak, suyun kullanımında en iyi verimi sağlayacak kademe sayısı hesaplanarak pompa hesabı yapılır. Sondaj makinalarıyla açılan bu kuyuların çapları pompa çapına bağlı olarak seçilir; elektrik motoruyla tahrik etme imkânı varsa, elektrik motorunun çapı da pompa çapına uygun olarak seçilmiş olur (Gölcü, 2002).

Makalede tarımsal sulamada yoğun olarak kullanılan derin kuyu su pompalarının debi verilerinin Yapay Sinir Ağlarında kullanılmasıyla arıza tespiti hedeflenmiştir.

Derinkuyu Su pompaları ikiye ayrılır.

a) Dalgiç pompalar,

b) Düşey milli pompalar.

Dalgıç pompalar ile düşey milli pompalar arasındaki temel fark pompa fanlarını çeviren tahrik elemanının yerleştirildiği konumdur. Günümüzde en çok kullanılan tipi dalgıç pompalardır. 


\section{Düşey Milli Pompa (Vertical Turbine Pump)}

İlk defa M. Layne tarafından icat edilmiştir. Günümüzde elektriğin olmadığı ve yakın mesafeli kuyularda ya da diğer pompalarca çekilmesinin mümkün olmadığı su seviyesine sahip kuyularda kullanılacak şekilde ayarlanmıştır.

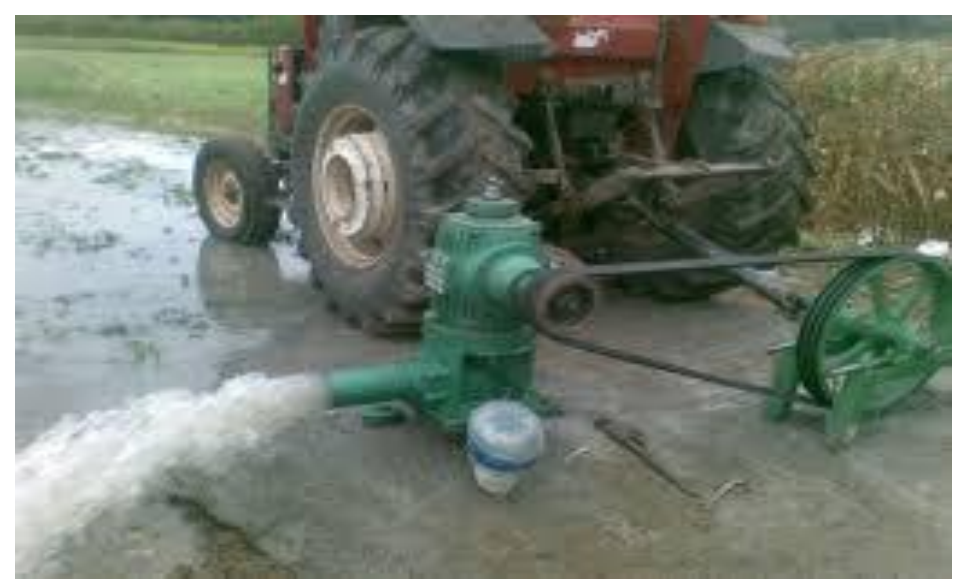

Şekil 2. Düşey Milli Pompa

Figure 2. Vertical Shaft Pump

Şekil 3’ de de görüldüğü gibi milli pompa sistemi 3 ana kısımdan oluşur. Bunlar Pompa kısmı, Kolon kısmı ve Çıkış kısmından oluşmaktadır. Çıkış kısmı, motordan ve ya traktör şaftından, pompa için gerekli devri oluşturan bir dişli kutusundan (şanzıman) çıkış başlığından oluşmaktadır. Pompa, fan için gerekli devri ve gücü üreten ve suyun sulama sistemine ulaşmasını sağlayan kısımdır. Kolon kısmı, demir sanayi boruları ve gerekli çaplarda ki miller yardımı ile pompa sisteminin kuyuda asılı kalmasını sağlar. Boruların içinde bulunan miller aracılığı ile şanzımandan aldığı torku, pompa fanlarına ulaştırır. Böylece pompanın dönmesini sağlayan kısımdır. Pompa kısmı, yeraltında suyun içinde yer alır, millerden aldığı devir ile pompanın içinde bulunan fanlar yardımı ile suyu yeryüzüne iletir.

Milli pompa dezavantajları;

- Mil kesme

- Yağ Tüketimi

- Şanzıman Bakımı

- Pompa Montajının Zor Olması

- Konik Helis Dişli ve ya Kayış Kasnak Sistemleri Kullanımından Kaynaklanan Şanzıman Maliyeti

- Gürültülü Çalışması

Yukarıda verilen sebeplerden dolayı milli pompa günümüzde yerini dalgıç pompalara bırakmıştır. 


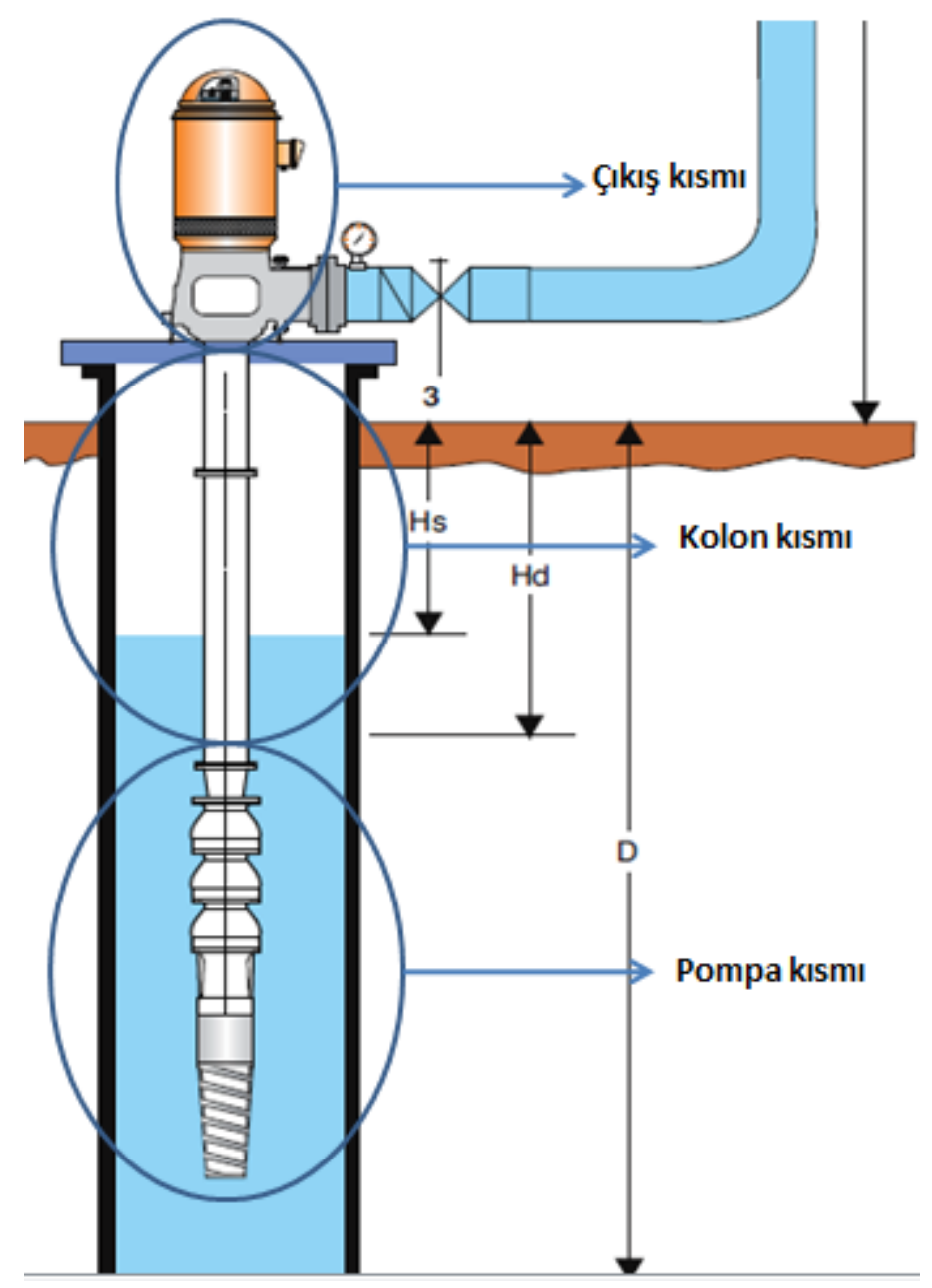

Şekil 3. Düşey Milli Pompa Şeması

Figure 3. Vertical Shaft Pump Diagram

$\mathrm{H}_{\mathrm{S}}$ : Statik su seviyesi

$\mathrm{H}_{\mathrm{D}}$ : Dinamik su seviyesi

$\mathrm{D}$ : Kuyu derinliği

\section{Dalgıç Pompalar (Submersible Pump)}

Pompa kısmı yukarıda, motor kısmı aşağıda olacak şekilde ve birbirlerine monte edilmiş olarak dik bir şekilde kuyuya indirilir. Bu nedenle bunlara "Dalgıç Pompa" denilir.

Dalgıç pompalarda kullanılan çarkların dönüş yönü Kuzey Yarım Kürede dünyanın dönüş yönü sebebi ile saat ibreleri yönüdür. Sebebi ise Coriolis ivmesi (kuvveti) ile birlikte hareket etmesidir (Çalışır, 2005).

Dalgıç pompalar genelde çıkış çaplarına göre 4 inç, 5 inç, 6 inç, 8 inç, 10 inç ve 14 inçlik seri halde imal edilirler. Dalgıç pompa ünitesi çok kademeli santrifuj pompanın su altında çalışmaya uygun bir elektrik motoruna monte edilmesinden meydana gelmiştir. Pompa miline güç aktarımı dalgıç asenkron motorlar yardımı ile aşağıdan gerçekleşir. Oluşabilecek eksenel yükler ise özel olarak dalgıç asenkron motor aracılığ 1 ile sağlanır. Elektrik enerjisi, asenkron motora kolon sistemi boyunca yüzeyden sarkıtılan kablolarla iletilir. 


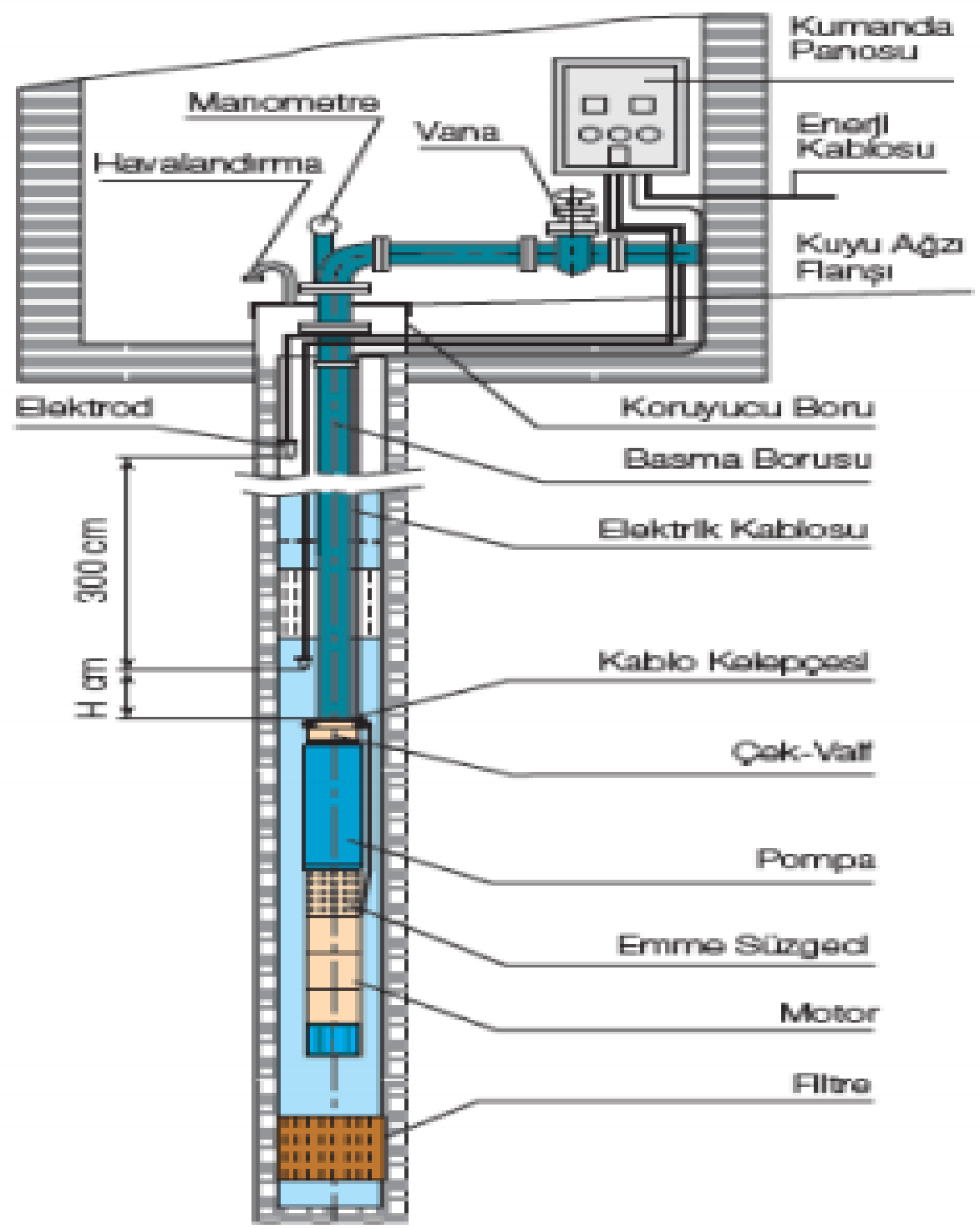

Şekil 4. Dalgıç Pompa Şeması

Figure 4. Submersible Pump Diagram

Asenkron motor; Dalgıç Asenkron Motorlar (DASM), asenkron motorların özel bir tipi olup, tasarımı ve özellikleri biraz farklılık göstermektedir. DASM'lar, dalgıç pompa ile birlikte su içerisinde çalıştığından motorun soğutulması hava yerine su ile yapılmaktadır. Gücü $7.5 \mathrm{~kW}^{\prime}$ a kadar olan DASM'lara "doğrudan", $11 \mathrm{~kW}$ ve daha büyük güçte olan DASM'lara "yıldız-üçgen" yol verilmektedir (Çunkaş, 2012).

Kolon boruları: Pompanın ve motorun kuyunun içinden çektiği suyun yeryüzüne ulaşmasını sağlar Pompa çapına göre 3 inç, 4 inç, 6 inç, 8 inç, anma çaplarında değişir. Borular genellikle 3 metre ve ya 6 metre olarak boru ağızlarına diş çekilerek ovalama ve bilezikli olarak üretilmektedir. Pompanın montaj derinliğine göre demir sanayi borusu ve ya plastikten imal edilir.

Elektrik kablosu: Trifaze motorlu pompalar için pompanın derinliğine göre yassı kablolardır. Pompa montaj derinliği arttıkça kablo kalınlıkları artar.

Kumanda panosu: Pompanın motoruna elektrik akımını veren sistemdir. İçerisinde bulunan kontaktörler, termik ve motor koruma ve sıvı seviye röleleri ile pompa motorunun gelen voltaja göre akımı düzenleyerek motorun çalışmasını sağlar. Röleleri sayesinde motorun kullanım ömrünü uzatır. Zaman ve basınç röleleri ile de kullanıma uygun zamanlamayı ayarlar (Bulca, 2017). 
Kuyu ağzı flanşı pompanın kuyuda sabit durmasını sağlayan yerine göre 5 ile 50 ton arasında yük taşıyan bileşendir.

Emme süzgeci, motor ve pompa arasına yerleştirilir. Kuyuda bulunan çakıl benzeri katı tanelerin pompa fanlarına ulaşmasını engeller. Pompanın ömrünü uzatır.

Çek-valf, pompanın çıkışı ve kolon borusu arasında bulunur. Sistemin çalışması durduğunda kolon boruları içerisindeki suyun kuyunun içerisine akmasını engeller. Faydası pompanın ve motorun ters dönüş yapmasını engeller. Otomatik çalışan sistemler için gereklidir. Otomatik çalışmayan sistemler için ise motorun ilk kalkışta fazla yüke binmesini sağlar. Bundan dolayı kullanılmaması gerekir.

Kablo kelepçesi, elektrik motoruna ulaşan kablonun sabit bir Şekilde durmasını sağlar.

Elektrod, sıvı seviyesini belirler. Su bittiğinde sistemi durdurur.

Basma borusu, sistemi taşıyan elemandır.

Koruyucu Boru, kuyunun içine yabancı madde girmesini engeller.

Diğer bileşenler vana su taşıma tesisatına yön veren bileşendir. Tüm vanaların kapatılması durumunda pompa anlık olarak yüksek akım çekeceğinden dolayı motor arızalanabilir, dikkat edilmelidir.

Pompa tipinin seçiminde bilinmesi gereken çalışma şartlarının değişkenleri başlıca şunlardır: Debi (Q) ve çalışma noktasında istenilen basma yüksekliği $(H)$ değerleridir. Pompanın büyüklüğü ve devri, pompa seçim eğrilerinden belirlenir. Seçilen pompanın verim, pompa motorunun gücü ve diğer parametreleri de pompa performans eğrilerinden okunur (Goncaoğlu, 2010).

1- Pompa debisi: $\mathrm{Q}$ ile gösterilir, birim zamanda pompadan geçen sıvının hacmidir. Yaygın olarak $\left[\mathrm{m}^{3} / \mathrm{h}\right] \quad$ ve $\quad[\mathrm{lt} / \mathrm{sn}] \quad$ birimleri kullanilır.

2- Pompa basma yüksekliği: H ile gösterilir, pompa tarafından akışı sağlanmak istenilen sıvıya verilen faydalı kinetik enerjidir. Yaygın olarak $[\mathrm{m}]$ birimi kullanılır. 3- Sistemin basma yüksekliği: Sistemin basma yüksekliği H aşağıdaki gibi belirlenir:

$\mathrm{H}=\mathrm{h}+\mathrm{TDP}+\boldsymbol{P}_{\boldsymbol{A}}$ formülü ile bulunur.

H; Basılacak sıvının serbest sıvı yüzeyi ile basıldığı yer arasındaki statik yükseklik farkıdır.

TDP; Tüm basınç kayıplarının toplamıdır. Bu toplam basınç farkı emiş ve basma hattındaki borulardaki sürtünme kayıpları, tüm vana, armatür ve partiküllerin sürtünme kayıplarından oluşur.

$\boldsymbol{P}_{\boldsymbol{A}}$ : Akma basıncı basma hattının sonunda sıvının vana armatür veya borudan akış basıncıdır (Goncaoğlu,2010). 
Çizelge 1. Su Borularındaki sürtünme kaybı Table 1. Friction loss in water pipes

\begin{tabular}{|c|c|c|c|c|c|c|c|c|c|}
\hline \multicolumn{2}{|c|}{ SU BORULARI ANMA ÇAPLARI } & $3 / 4^{\prime \prime}$ & $1 "$ & $1 " 1 / 4$ & $1 " 1 / 2$ & $2 "$ & $2 " 1 / 2$ & $3^{\prime \prime}$ & $4 "$ \\
\hline $\mathrm{m}^{3} / \mathrm{h}$ & $1 / \mathrm{s}$ & \multicolumn{8}{|c|}{ Düz döküm boruların her 100 metresindeki sürtünme kaybı } \\
\hline 1,2 & 0,3 & 10,4 & 3,7 & 1 & 0,3 & & & & \\
\hline 1,5 & 0,4 & 15,8 & 5,7 & 1,5 & 0,5 & & & & \\
\hline 1,8 & 0,5 & 22,3 & 8 & 2,1 & 0,7 & & & & \\
\hline 2,1 & 0,6 & 29,8 & 10,8 & 2,8 & 0,9 & 0,3 & & & \\
\hline 2,4 & 0,7 & 38,2 & 13,8 & 2,7 & 1,2 & 0,4 & & & \\
\hline 3 & 0,8 & 58,2 & 21,1 & 8 & 1,8 & 0,6 & & & \\
\hline 3,6 & 1 & 82 & 30 & 10,8 & 2,5 & 0,9 & & & \\
\hline 4,2 & 1,2 & & 40 & 13,9 & 3,3 & 1,2 & & & \\
\hline 4,8 & 1,3 & & 51,5 & 17,5 & 4,3 & 1,4 & & & \\
\hline 5,4 & 1,5 & & 64 & 21,4 & 5,4 & 1,8 & 0,5 & & \\
\hline 6 & 1,7 & & 79 & 33 & 6,6 & 2,2 & 0,6 & 0,2 & \\
\hline 7,5 & 2,1 & & & 47 & 10 & 34 & 0,9 & 0,4 & \\
\hline . & . & & & & & & & & \\
\hline 16 & 4,2 & & & & 37,5 & 12,3 & 3,2 & 1,1 & 0,4 \\
\hline \multicolumn{3}{|c|}{ PVC boru için çarpan } & \multicolumn{7}{|c|}{0,65} \\
\hline \multicolumn{3}{|c|}{ Alüminyum boru için çarpan } & \multicolumn{7}{|c|}{0,7} \\
\hline \multicolumn{3}{|c|}{ Çelik boru için çarpan } & \multicolumn{7}{|c|}{0,8} \\
\hline \multicolumn{3}{|c|}{ Az paslı boru için çarpan } & \multicolumn{7}{|c|}{1,25} \\
\hline
\end{tabular}

Yukarıdaki kullanılan tablo Suteksan sulama sistemleri A.Ş’ nin kataloglarından faydalanılmıştır.

Belirtilen $\mathrm{H}$ yüksekliğini net olarak bulabilmek için üstteki tablodan pompanın kuyuya indiği derinliği bilmemiz yetmez, yer altındaki kuyulardan çıkan suların elbette bir basacağı mesafe ulaşabileceği bir uzaklık olur. Bu uzaklıklara üstteki sürtünme kaybı hesap çizelgesinden ulaşılır. Örnek olarak; Derinliği 148 metrede $16 \mathrm{~m}^{3} / \mathrm{h}$ su veren bir pompa için 2" veya $63 \mathrm{~mm}$ diş çapa sahip boru için sürtünme kaybı tablodan 12,3 okunur.

plâstik boru için çarpan 0,65 olarak verilmiştir. $12,3 * 0,65 * 3=24$

$148+24=172$

Yani pompa seçimi 172 metreden olacakmış gibi yapılır.

Pompanın işletim noktasındaki debisi $\mathrm{Q}\left[\mathrm{m}^{3} / \mathrm{h}\right]$, basma yüksekliği $\mathrm{H}[$ metre], akışkanın yoğunluğu $\mathrm{p}[\mathrm{kg} / \mathrm{dm} 3]$ birimleriyle ve pompa verimi $\mathrm{n}$ ise ilgili pompa eğrisinden alınarak formülde yerine konulduğunda, gerekli olan asgari motor gücü $\mathrm{P}[\mathrm{kW}]$ olarak bulunur. Kullanılan akışkan su olduğunda $\mathrm{p}=1\left[\mathrm{~kg} / \mathrm{dm}^{3}\right]$ kabul edilerek dikkate alınmaz. Emniyet faktörü ise kullanılacak motorun nominâl gücüne aşağıda verilen oranlarda emniyet payı eklemekle bulunur (Goncaoğlu, 2010).

$\mathrm{P}<=1,5 \mathrm{~kW}$ lik mil gücü için $f_{\text {emniyet }}=1,15$

$\mathrm{P}<=15 \mathrm{~kW}$ lık mil gücü için $f_{\text {emniyet }}=1,1$

$\mathrm{P}>15 \mathrm{~kW}$ lık mil gücü için $f_{\text {emniyet }} \quad=1,05$

$\mathrm{Q}=\frac{(\mathrm{P} .1000 . \eta)}{(\rho . \mathrm{g} \cdot \mathrm{H})}$

Suyun yoğunluğu ve yer çekimi ivmesinin sabit olmasından dolayı

$\mathrm{Q}=\frac{(\mathrm{P} .367 . \eta)}{\mathrm{H}}$

Q: hava debisi $\left(\mathrm{m}^{3} / \mathrm{s}\right)$

P:Güç (W)

$\eta$ : Verim

@: yoğunluk $\left(\mathrm{kg} / \mathrm{m}^{3}\right)$

g: yerçekimi ivmesi $\left(9.81 \mathrm{~m} / \mathrm{s}^{2}\right)$

H: Yükseklik (m)

UMTS 2019: 19. Ulusal Makina Teorisi Sempozyumunda sunulan bildiriler arasından seçilmiştir. (4-6 Eylül 2019 İskenderun, TÜRKIYYE) 
Çizelge 2. Dalgıç pompa seçim tablosu

Table 2. Submersible pump selection table

\begin{tabular}{|c|c|c|c|c|c|c|c|c|c|c|}
\hline \multirow[b]{2}{*}{ Pompa tipi } & \multirow[b]{2}{*}{ Güç(kW) } & 0 & 10 & 12 & 14 & 15 & 16 & 17 & 18 & 20 \\
\hline & & \multicolumn{9}{|c|}{ STATIK BASMA YÜKSEKLİKLERİ(Metre) } \\
\hline $616 / 01$ & 0,65 & 11 & 10 & 9 & 8 & 8 & 7 & 7 & 6 & 5 \\
\hline $616 / 02$ & 1 & 23 & 20 & 19 & 16 & 14 & 16 & 15 & 14 & 12 \\
\hline $616 / 03$ & 1,1 & 34 & 31 & 29 & 27 & 25 & 25 & 24 & 22 & 19 \\
\hline $616 / 04$ & 1,5 & 45 & 41 & 38 & 36 & 35 & 33 & 31 & 29 & 25 \\
\hline $616 / 05$ & 2,2 & 56 & 52 & 49 & 48 & 44 & 42 & 45 & 37 & 32 \\
\hline $616 / 06$ & 2,2 & 68 & 63 & 60 & 56 & 54 & 51 & 49 & 46 & 39 \\
\hline $616 / 07$ & 3 & 79 & 73 & 63 & 61 & 60 & 59 & 56 & 53 & 45 \\
\hline $616 / 08$ & 4 & 90 & 80 & 80 & 75 & 72 & 60 & 65 & 61 & 55 \\
\hline $616 / 09$ & 4 & 102 & 94 & 90 & 84 & 91 & 77 & 71 & 68 & 59 \\
\hline $616 / 10$ & 4 & 111 & 104 & 99 & 92 & 80 & 85 & 81 & 76 & 65 \\
\hline $616 / 11$ & 6,5 & 125 & 114 & 108 & 104 & 99 & 90 & 96 & 85 & 73 \\
\hline $616 / 12$ & 6,5 & 135 & 120 & 111 & 107 & 100 & 104 & 98 & 78 & 79 \\
\hline $616 / 13$ & 6,5 & 146 & 137 & 130 & 122 & 117 & 112 & 106 & 99 & 86 \\
\hline $616 / 14$ & 7,5 & 156 & 147 & 141 & 137 & 127 & 124 & 115 & 109 & 93 \\
\hline $616 / 15$ & 7,5 & 169 & 158 & 151 & 141 & 136 & 130 & 123 & 116 & 100 \\
\hline $616 / 16$ & 7,5 & 180 & 168 & 160 & 156 & 144 & 140 & 131 & 123 & 106 \\
\hline $616 / 17$ & 7,5 & 190 & 180 & 172 & 169 & 163 & 158 & 138 & 130 & 112 \\
\hline $616 / 18$ & 9,2 & 200 & 183 & 181 & 169 & 164 & 153 & 140 & 139 & 120 \\
\hline $616 / 19$ & 9,2 & 214 & 198 & 190 & 178 & 172 & 164 & 155 & 146 & 126 \\
\hline $616 / 20$ & 9,2 & 224 & 216 & 200 & 183 & 180 & 172 & 163 & 154 & 132 \\
\hline $616 / 21$ & 15 & 236 & 222 & 211 & 200 & 190 & 181 & 173 & 163 & 141 \\
\hline
\end{tabular}

Yukarıdaki tabloda Suteksan sulama sistemleri A.Ş'nin kataloglarından faydalanılmıştır. Tablo deneme kuyularında ultrasonik debimetre aracılığı ile debi verileri elde edilmiştir. Sonuç olarak parametrelerimiz olan 172 metreden saatte $16 \mathrm{~m}^{3}$ su verecek pompa, 616 serisi 20 kademeli pompa çizelge 1 de siyah taralı kısım seçilir. 
Çizelge 3. Elektrik kablosu seçim tablosu

Table 3. Electrical cable selection table

\begin{tabular}{|c|c|c|c|c|c|c|c|c|c|c|c|}
\hline \multicolumn{12}{|c|}{ YILDIZ ÜÇGEN BAĞLANTISI } \\
\hline \multicolumn{2}{|c|}{ GÜÇ } & \multirow{3}{*}{$\begin{array}{c}\mathrm{V} \\
\mathrm{O} \\
\mathrm{L} \\
\mathrm{T} \\
\mathrm{A} \\
\mathrm{J} \\
\end{array}$} & \multicolumn{9}{|c|}{ KABLO KESİII $3 X \ldots \mathrm{mm}^{2}$} \\
\hline \multirow[t]{2}{*}{$\mathrm{HP}$} & \multirow[t]{2}{*}{ KW } & & 1,5 & 2,5 & 4 & 6 & 10 & 16 & 25 & 35 & 50 \\
\hline & & & \multicolumn{9}{|c|}{ MAKSIMMUM UZUNLUK(Metre) } \\
\hline 4 & 3 & \multirow{11}{*}{$380 \mathrm{~V}$} & 140 & 230 & 370 & & & & & & \\
\hline 5,5 & 4 & & 100 & 170 & 270 & 400 & & & & & \\
\hline 7,5 & 5,5 & & 70 & 120 & 200 & 300 & 500 & & & & \\
\hline 10 & 7,5 & & 57 & 90 & 150 & 220 & 380 & & & & \\
\hline 12,5 & 9,2 & & 46 & 70 & 120 & 180 & 310 & 490 & & & \\
\hline 15 & 11 & & 39 & 60 & 100 & 150 & 250 & 400 & & & \\
\hline 17,5 & 13 & & & 55 & 90 & 130 & 230 & 355 & & & \\
\hline 20 & 15 & & & 50 & 80 & 110 & 200 & 310 & 490 & & \\
\hline 25 & 18,5 & & & & 60 & 90 & 160 & 250 & 400 & 560 & \\
\hline 30 & 22 & & & & 50 & 70 & 130 & 210 & 340 & 470 & \\
\hline 35 & 26 & & & & 46 & 68 & 110 & 180 & 290 & 410 & \\
\hline
\end{tabular}

Yukarıdaki tabloda Suteksan sulama sistemleri A.Ş'nin kataloglarından faydalanılmıştır Sonuç olarak 9,2 kw motor için 180 metre de verimli çalışabilmesi için 3x6 Yassı kablo seçilir.

\section{Paslanmaz Çelik Dalgıç Pompa Kısımları (Stainless Steel Submersible Pump Parts)}

Çıkış: Pompadan kolon borularına çıkış sağlanıldığı kısımdır.

Fırlatıcı ve somun: Fandan suyun ayrıldığı kısımdır.

Fan lastiği: Fan ve difizör arasında bulunur. Sürtünmeyi azaltır

Mil lastiği: Mil ve fan arasında bulunur. Milin aşınmasını ve kesilmesini önler

Fan: Yaptığı dönme ile içerisinde bulunan kanatlar yardımı ile Merkez kaç yöntemi ile suyun difizör kanatçılarına yönlendirerek suyu basınçlandırır.

Difizör: Fanın basınçlandırdığı suya yön verir ve ekipmanların birleşimine yardımcı olur.

Mil: Birden fazla fan ve difizörü birbirine bağlar fana tahriği veren elemandır.

Kaplin: Motor ve fan milini birbirine bağlayan elemandır.

Kablo muhafazası: Kablonun sabitlenmesini sağlar ve korur.

Birleştirme Kuşağı: Tüm ekipmanların bir arada tutunmasını sağlar. 


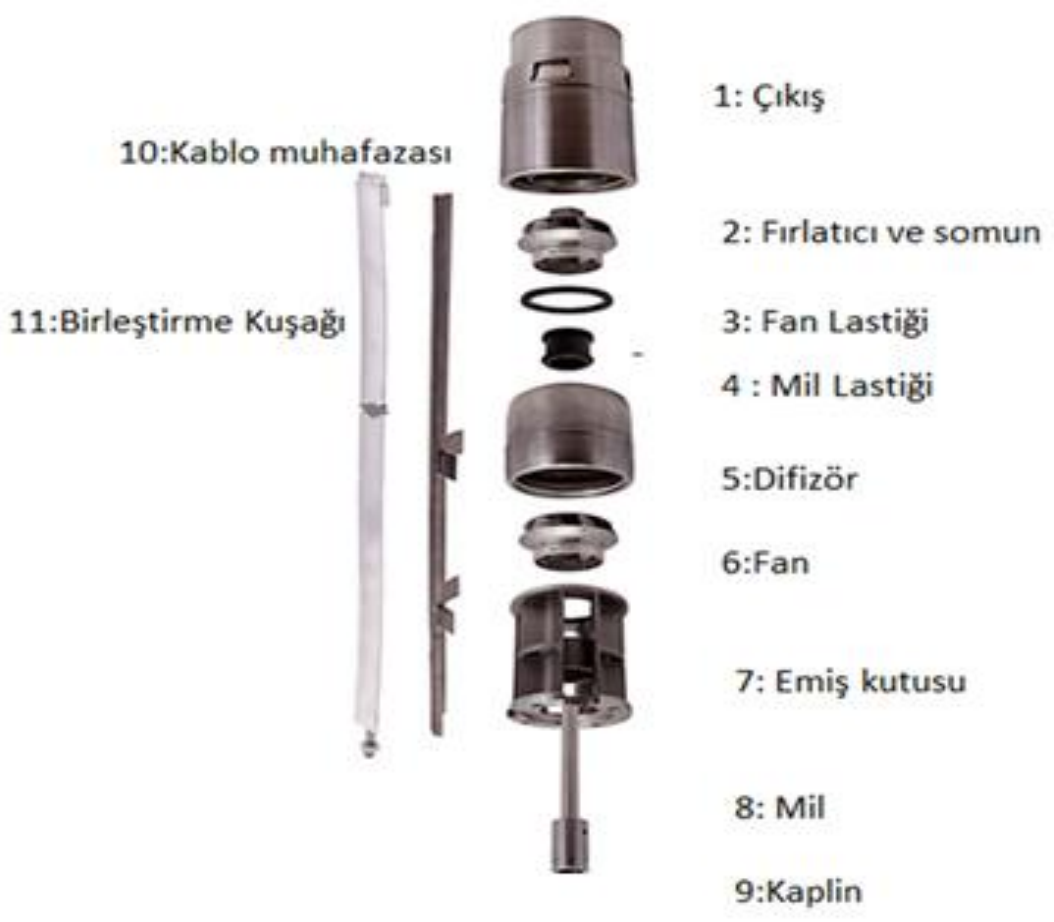

Şekil 5. Krom dalgıç pompa

Figure 5. Chrome submersible pump

\section{Dalgıç Pompa Kullanımında Dikkat Edilmesi Gereken Hususlar (Submersible Pump Considerations)}

- Pompanın kuyuya montajından önce, hem kuyunun, hem de pompanın kullanım amacına uygun olduğundan emin olunmalıdır. Kuyu debisinin kullanıcının ihtiyacını karşılamaya yeterli olduğu kontrol edilmeli, monte edilecek pompanın debi ve basma yüksekliğinin amaca uygun olduğu görülmelidir.

- Kuyunun kum temizliği yapılmış olmalı, akışkan içerisindeki kum, tortu vb. partikül miktarının pompanın işletme limitlerini aşmadığından emin olunmalıdır.

- $\quad$ Pompa asla kuyunun dibine kadar indirilmemeli, motorun alt noktası kuyu dibinden asgari 2 m daha yukarıda olacak Şekilde monte edilmelidir.

- Dalgıç motorun yeterli soğutulabilmesi için, motor çevresinde yeterli akışkan akışının sağlandığından emin olunmalıdır

- Elektrik kontrol panolarının elektrik şebekesinden kaynaklanabilecek, yüksek veya düşük voltaj, fazlar arasında voltaj dengesizliği vb. sorunlarda dalgıç motorun korunmasını sağlayabilecek düzeyde olması gerekmektedir

- Ayrıca pompanın bulunduğu kuyu da sıvı seviye röleleri bağlantıları düzenli olarak yapilmalıdır.

Dalgıç Pompalarda Arıza Tipleri (Failure Types in Submersible Pumps)

Voltajın düşük gelmesi: Voltajın düşük gelmesi durumunda motor koruma röleleri rölesi yoksa dalgıç motoru arızalanabilir.

Motorun imalatın kaynaklı hatalar: Motorun imalatında yataklamaların kaliteli malzemeden ve gerekli ölçülerde imal edilmemesi durumunda motorun kullanım ömrü azalır.

Kuyunun susuz olması: Kuyunun susuz olması durumunda motor arızalanabilir veya pompaları aşırı sürtünmeden kaynaklanan ısı ile aşınır Mil keser motoru zorlar motor arızalanır. 
Pompa montajında bulunan boruların delinmesi: Bu durumda delinen borulardan aşırı basınçta su kaybı yaşanır. Delinen borudan sızan su kuyunun yıkılmasına sebep olur. Kuyu yıkılınca pompa sistemi görevini yapamaz hale gelir.

Pompa kademesinde kullanılan malzemeler: Pompa sisteminde kullanilan malzemeler suyun sertlik derecesine asitlik oranına göre değiştirilmelidir.

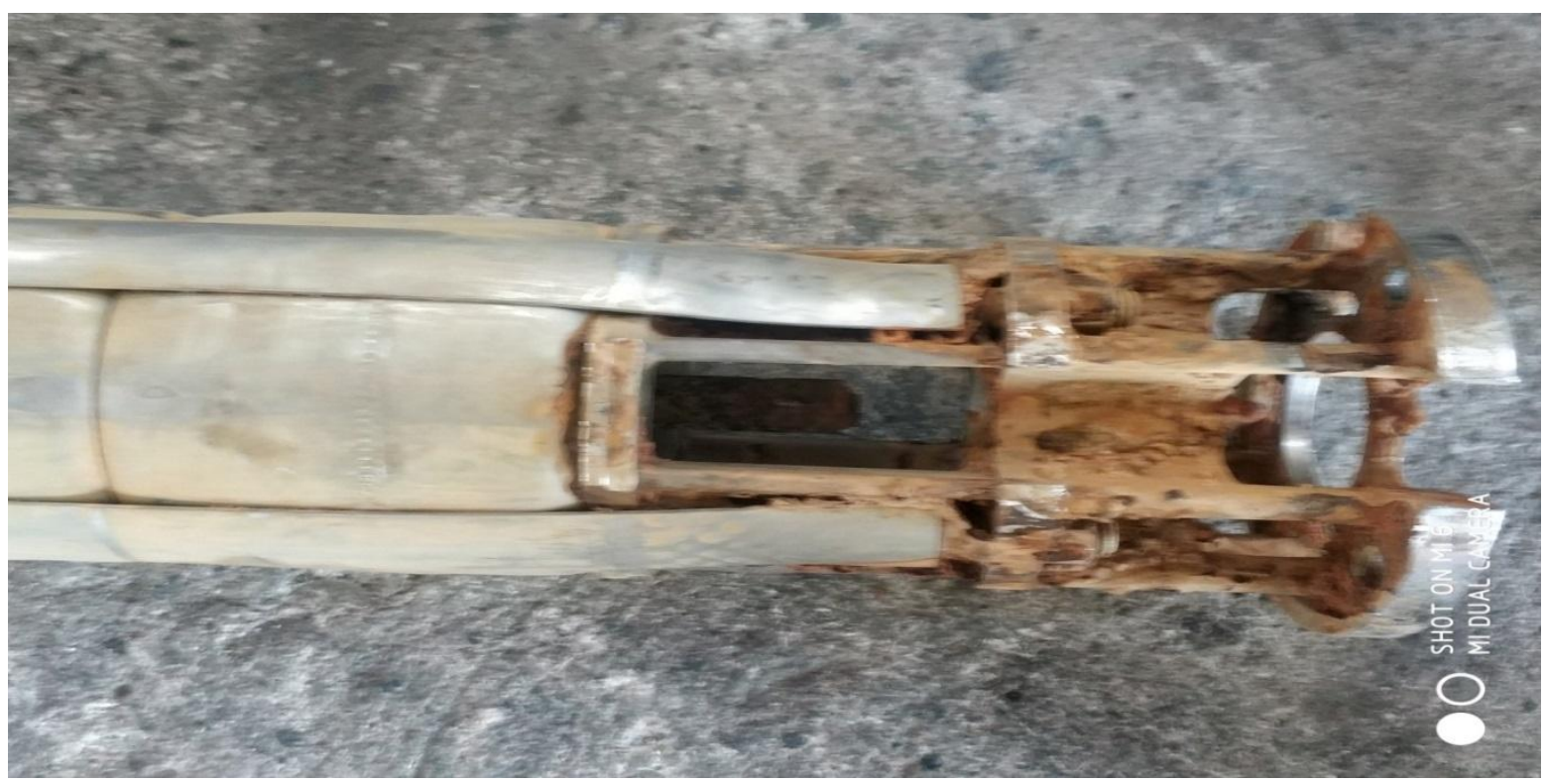

Şekil 6. Hatalı malzeme kullanımı sonucu kaplinin kopması

Figure 6. Breakage of coupling due to incorrect material use

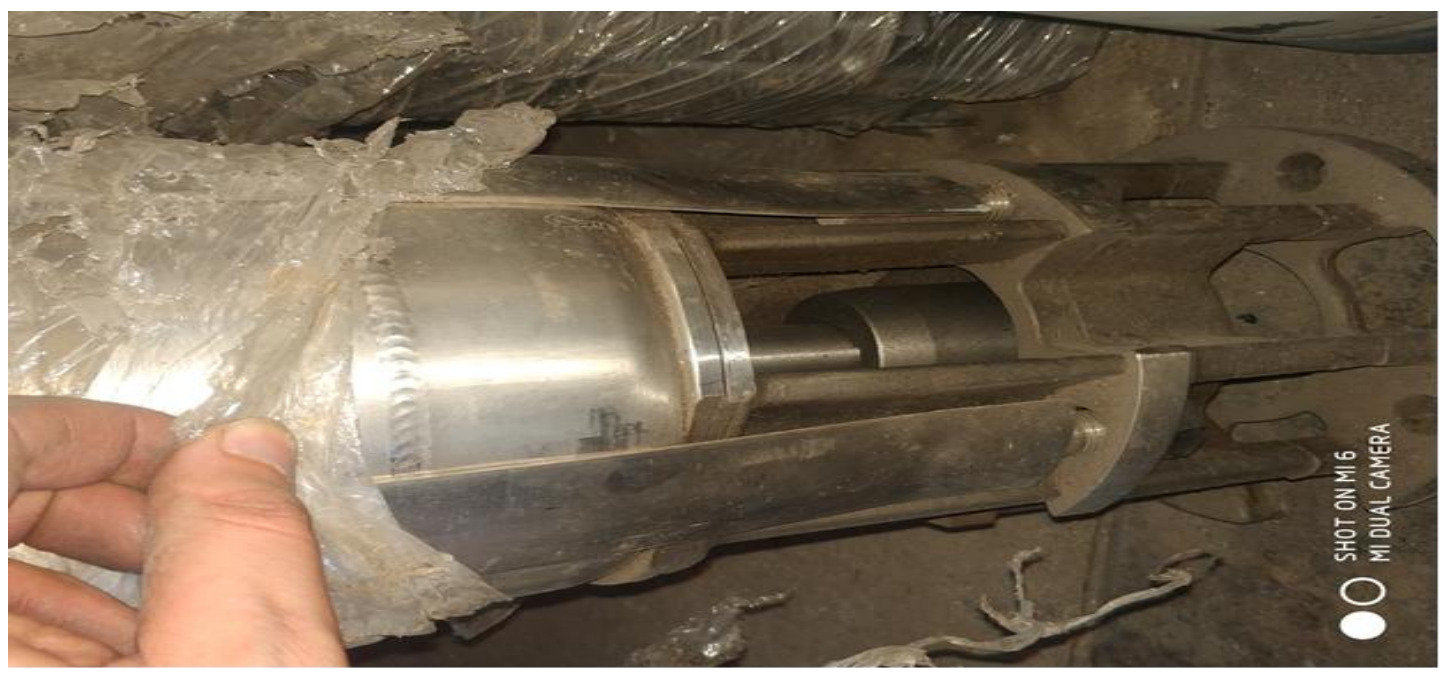

Şekil 7. Yeni dalgıç pompa

Figure 7. New submersible pump

Şekil 5' de görüldüğü gibi pompa milinin motor ile birleştiği konumda bulunan kaplin hatalı malzeme kullanımı sonucu acı (asitli) suyun içinde eriyerek yok olmuştur. Şekil 6' da ise pompanın kaplininin çalışmadan önceki hali görülmektedir.

Pompanın imalatından kaynaklanan sorunlar: Pompanın difüzörleri istenilen toleranslar da işlenmediğini den dolayı sürtünmeden kaynaklanan zamanla boşluklar elde edilir. Bu boşluklar pompanın verimini düşürür. Daha fazla elektrik tüketmesini sağlar. Debiyi azaltır.

Mil kesmesi veya aşınması: Aşağıdaki Şekillerde görüldüğü gibi pompa fanlarının tutunduğu miller aşınırsa pompa fanları dönmez ve pompa işlevini kaybetmiş hale gelir. 

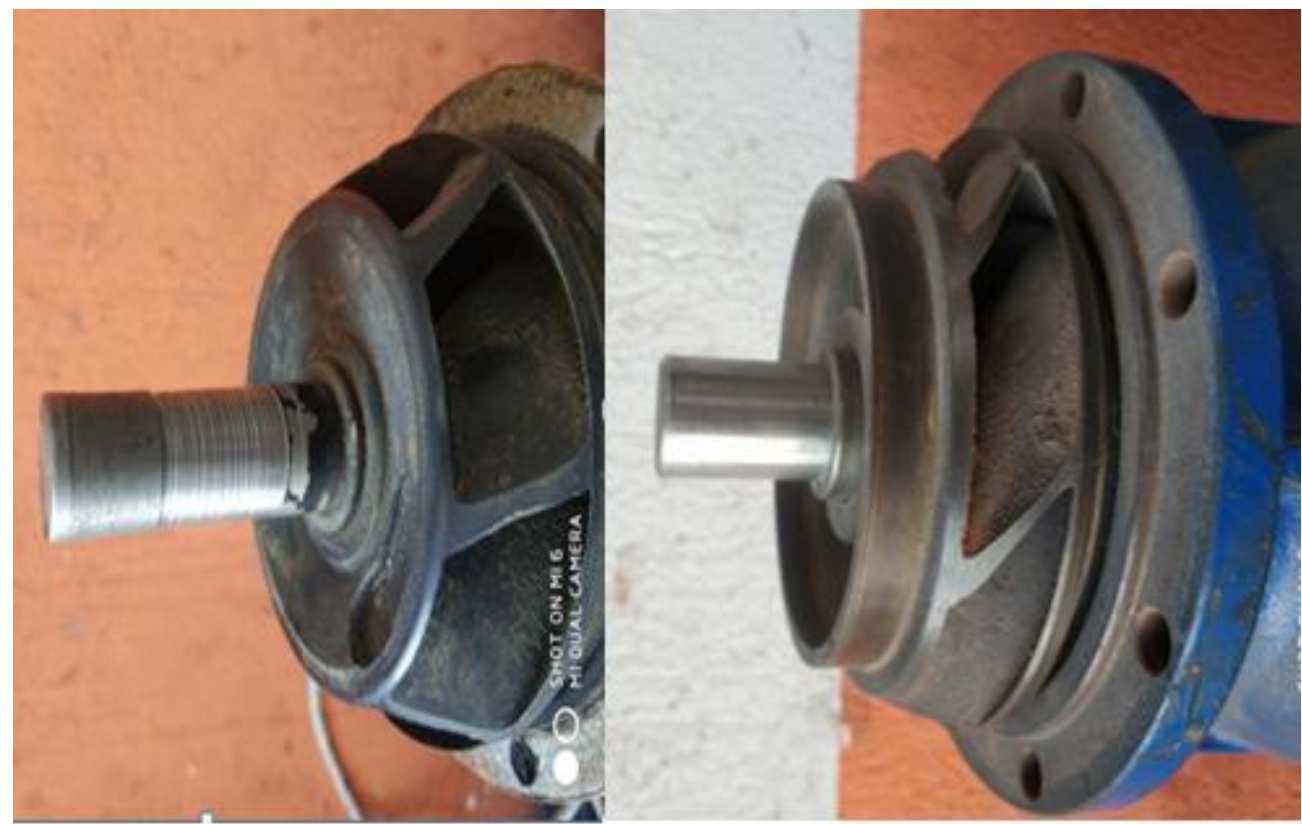

Şekil 8. Mil aşınması

Figure 8. Shaft amortization

Deneysel Veriler Ve Simulasyon Sonuçları (Experimental Data And Simulation Results)

Çizelge $2^{\prime}$ den alınan pompa basma yükseklikleri $(\mathrm{Hm})$ ve debileri $\left(\mathrm{m}^{3} / \mathrm{h}\right)$ cinsinden YSA programı olan qwik net e tanıtıldı. Qwik net programı giriş değerleri ve kendi oluşturduğu değerler ile grafikler oluşturdu. Bu değerler ve grafikler reel de elde edilen grafiklere benzer çıktığı belirlendi.

Örnek olarak verilen 616/20 serisi pompanın Ysa değerleri Çizelge 4' deki gibidir.

\section{Çizelge 4. Yapay Sinir A $\breve{g}$ verileri}

Table 4. Artificial neural networks data

\begin{tabular}{|c|c|}
\hline Output1 & Target1 \\
\hline 0,40493 & 0 \\
\hline 29,759219 & 30 \\
\hline 38,327754 & 38 \\
\hline 41,542827 & 42 \\
\hline 45,787572 & 46 \\
\hline 50,066754 & 50 \\
\hline 54,328842 & 54 \\
\hline 57,249588 & 58 \\
\hline
\end{tabular}




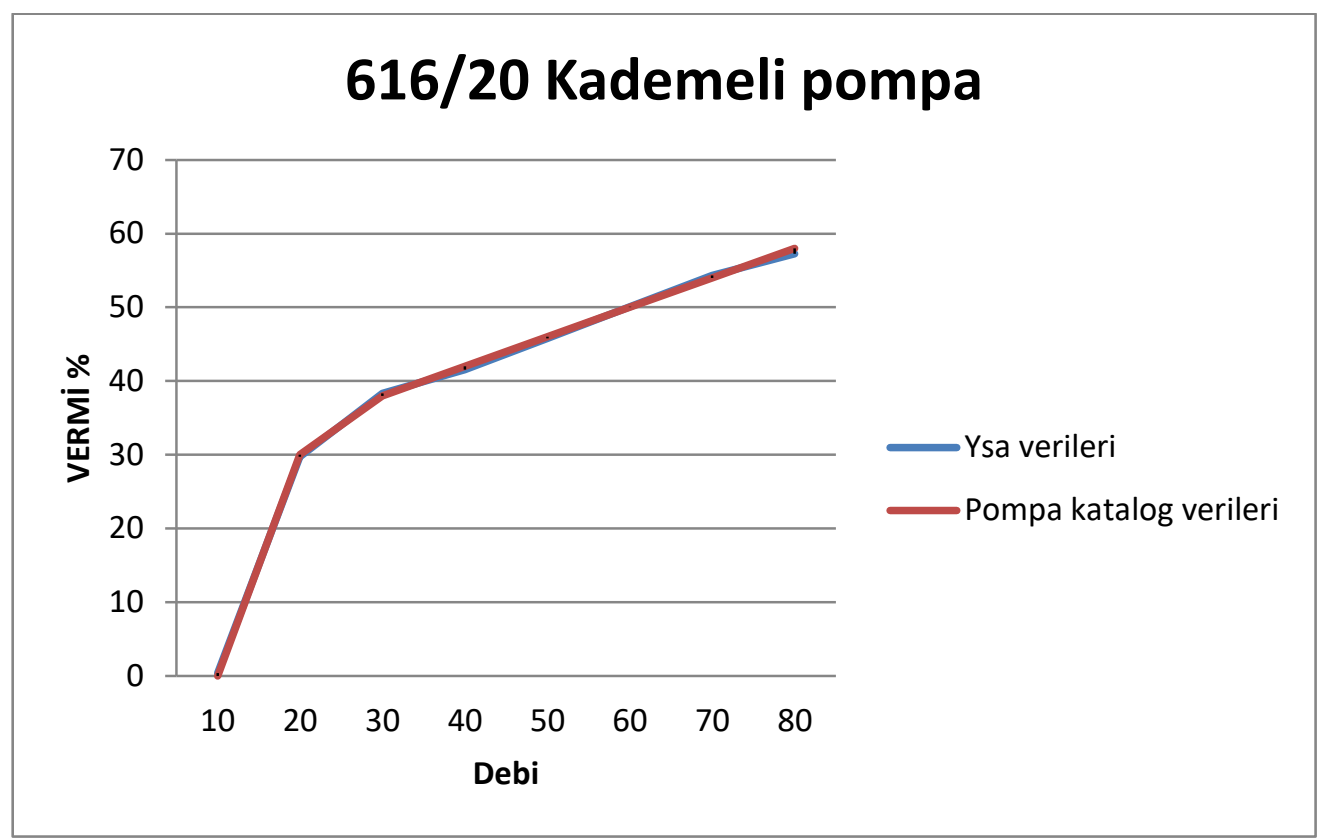

Şekil 9. YSA grafiği

Figure 9. Artificial neural networks graphic

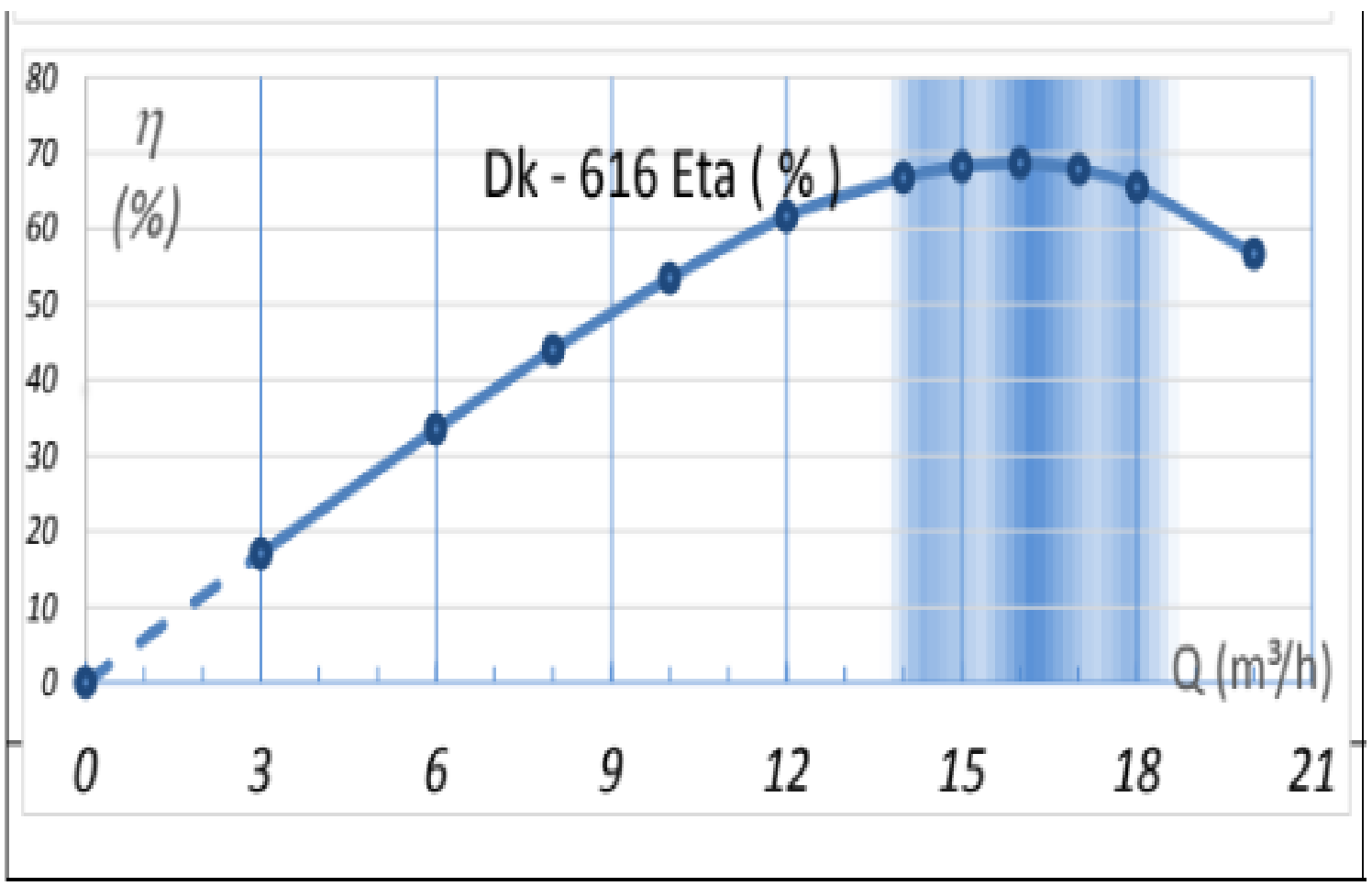

Şekil 10. Dalgıç Pompa Verim Grafiği

Figure 10. Submersible pump Efficiency Graphic

\section{SONUÇ ve TARTIŞMALAR (RESULTS and DISCUSSIONS)}

Yapılan bu çalışmada Dalgıç Pompa olarak DK Pompa markası seçildi. DK Pompa' nın pompa basma yüksekliği ve pompa debisi gibi teknik özellikler bakımından değerlendirilmiştir. Sonuç olarak, dikkate alınan teknik özellikler açısından Yapay Sinir Ağları yardımıyla bu tip pompalarda arıza tespiti UMTS 2019: 19. Ulusal Makina Teorisi Sempozyumunda sunulan bildiriler arasından seçilmiştir. 
sağlanabilinir. Başlangıç parametreleri olan 172 metre ve saatte $16 \mathrm{~m}^{3}$ için, Çizelge 2' den 616 serisi 20 kademeli pompa seçildi. Bu pompanın çalışması için 9,2 Kw dalgıç asenkron motor seçildi, bu motorun çalışması için gerekli 3x6 yassı kablo çizelge 3 de ki gibi seçildi. Çizelge 2' deki veriler Yapay Sinir Ağlarına aktarıldı ve Şekil 8' de ki grafik elde edildi. Elde edilen bu grafik Şekil 9' da ultrasonik debimetre yardımı ile elde edilen grafikle uyuştuğu tespit edildi. Pompa arızaları durumunda ultrasonik debimetreyle elde edilecek debi verileri, YSA programlarına aktarılıp elde edilen sonuçlar ile pompanın hangi hatayı verdiğinin tespiti yapılabilinir.

\section{KAYNAKLAR (REFERENCES)}

Bulca, E., 2017, “Dalgıç Pompa Sistemlerinin Değişim veya Onarımında Karar Süreci.”, Pompa ile Vana Dergisi, Teknik Makale No:URY-DP-008,

Çalışır, S., 2005, "Sulamada Kullanılan Dalgıç Pompalarda Dönüş Yönünün Sistem Verimine Etkisi." , Tarım Makinaları Bilimi Dergisi, Cilt 1, Sayı 2, ss. 123-134.

Çunkaş, M., 2012, "Dalgıç Motorlar Üzerinde Bir İnceleme.", Selçuk Üniversitesi Mühendislik-Mimarlık Fakültesi Dergisi, Cilt 27, Sayı 4, ss.4.

Goncaoğlu, B., 2010,"Pompa Seçimi Nasıl Yapılır." Yıldız Teknik Üniversitesi Çevre Mühendisliği Bölümü, İstanbul

Gölcü, M., 2002, "Kanat Sayısının Dalgıç Pompa Performansına Etkisi." , Sakarya Üniversitesi Fen Bilimleri Enstitüsü Dergisi, Cilt 6, Sayı 2, ss. 127-135. 